Bachman | Pedersen Zari | Enright | Lyn : Dulaney | Neveu

Kim | Bachman | Fisher : Hayes : Feldman: Grondzik

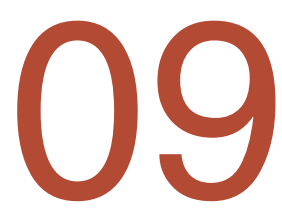

volume 6 | issue 1

\title{
A Case for Drawing
}

Francis Lyn, Florida Atlantic University

Ron Dulaney Jr. RA, West Virginia University

\begin{abstract}
Architecture faculty continue, at times contentiously, to debate the roles that hand drawing and digital media should have in the practices and education of architects. Some argue for the computer as the "new pencil," while others maintain that the pencil is irreplaceable. A survey conducted by the authors suggests that the academy itself may rest in a dichotomous position of committing more resources to digital media than hand drawing while simultaneously indicating that both types of media are valued about equally. Rather than reinforce an oppositional relationship between the hand and the computer, this paper aims to reveal current trends regarding the roles of hand and digital design media in the academy and to provide a review of the primary benefits of hand drawing within an environment that is, seemingly, preoccupied with digital media.
\end{abstract}

Hand drawing provides unique contributions to and opportunities within the development of architectural thought and work. Maintaining sketching and precision hand drawing as fundamental activities of the architect extends the post-Renaissance tradition of architecture as a distinct design discipline directed to architectural ideas and relationships. Furthermore, hand drawing creates unique opportunities for imaginative transformation, for bodily engagement and accommodation, and for preconditioning the qualities of a built work and therefore should remain a significant component of the discipline.

\section{Introduction}

\section{The Qualitative Argument}

Drawing, by definition, requires the presence of physical forces and resistances during the operational act. ${ }^{1}$ Between the tooth of the paper and the guided pressure of the hand, the tool leaves a residue of graphite or pigment on the page. While contemplating the anonymous quality of drawings produced by the limited palette of the plotter and its reams of paper, one might simultaneously consider how the built works of architects such as Carlo Scarpa or Louis Kahn would have differed without the presence of the hand in design. Among contemporary architects such as Greg Lynn, we may also observe that their work is also directly affected by the media with which they choose to design and represent their work. And even though it might be argued that various design media do not necessarily have a direct relationship to the architecture that is produced, it might be also argued that hand methods and materials (and the capacity for greater variety and combination through their continuance) allow for a level of interpretation that digital media do not. Certainly the expediency of digital media allows a type and efficiency of investigation that might not be otherwise possible. On the other hand, has this expediency, efficiency and easiness allowed us to forget or at least set aside the fact that there are other ways to engage architecture that also have value?

The discipline of drawing or designing by hand allows for the emergence and development of particular relationships between drawing, experience, and building. This paper reviews and reveals benefits of hand drawing and argues for maintaining the practice of hand drawing in educating the architect and making works of architecture. Although currently overshadowed by emerging digital design and fabrication processes (which the authors fully accept as a necessary component of the discipline), hand drawing, particularly free sketching and precision orthographic projection, must continue to be pervasively integrated into architectural education and practices.

\section{The Quantitative Argument}

In many schools of architecture, a conflict between hand drawing and digital media continues to be perpetuated. While some argue for the computer as the "new pencil", others maintain that the pencil cannot be replaced. And although some evidence suggests that hand drawing is becoming more marginalized as digital modeling has increased in scope and complexity, this does not seem to be a universally held position within academia. In fact, recent data collected from a survey of ACSA member schools ${ }^{2}$ seems to suggest that most programs ( $92 \%$ of respondents) view hand drawing and digital media as being more or less equally important to their pedagogies. This position, however, is contradicted by the amount of resources dedicated to hand drawing versus digital media. ${ }^{3}$ While $55 \%$ of survey respondents indicated that their programs offered three or more courses dedicated to digital media, only $35 \%$ indicated a similar number of courses dedicated to hand media. Similarly, while $83 \%$ of respondents indicated that digital media is introduced into their curriculum in a dedicated course, only $68 \%$ responded that hand media was introduced in a dedicated course. This discrepancy between what faculty members and administrators indicate should be taught and 
what they are actually teaching suggests a schism within the discipline, and begs the question: Why are more resources being dedicated to instruction in digital media, if both digital and hand media are perceived to be of equal pedagogical value?

Other evidence from this survey suggests that hand media is perceived as a more important tool of design pedagogy than digital media. While $85 \%$ of respondents had the opinion that a student's ability to draw by hand is directly related to their ability to design, only $52 \%$ held the same opinion with regard to digital media. So although both types of media are seen as having similar "pedagogical" value, hand media seems to be perceived as having greater "design" value.

Among respondents, there was also a sense that hand drawing might be more important to the foundation of an architect's education than digital media. In considering when various methods of delineation were introduced into curricula, over $85 \%$ indicated that hand methods were introduced in the first year, while about half as many (46\%) indicated that digital media was introduced within the same time frame.

This survey does suggest a dichotomous condition within curricula. It is, however, the position of the authors of this paper, that hand and digital media are not mutually exclusive. Nor do we believe that one is better than the other. Rather, it seems more important to determine how various methods of delineation might coexist in order to more fully express the breadth of the discipline. While resources are seemingly being redistributed from hand drawing to digital media, faculties do still believe that hand media is a critical component of architectural education. So even with the development of more agile and useful digital technologies, and the trends toward their significant implementation throughout academia and the profession, this paper aims to demonstrate that hand drawing should remain a significant and necessary component of the architectural curriculum.

\section{Freehand Drawing}

Among architecture faculty members and administrators who responded to the survey, freehand drawing and sketching is the most consistently introduced media during the first year of architectural education. Survey respondents also overwhelmingly related a student's ability to draw by hand with their ability to design. This data suggests that the activity of hand drawing, and free sketching in particular, are highly valued by educators as fundamental activities of the architect. Is this merely the residual inertia of architectural tradition since the Renaissance or does the sketch offer opportunities so far unmatched or perceived to be unmatched by digital media? While more objective research may be undertaken to understand why respondents value the hand sketch so highly and whether the hand drawing does in fact offer opportunities unmatched by digital media, this paper seeks to clarify the traditional role of hand sketching as a fundamental activity of the architect.

Bryan Lawson, in writing about the nature of architectural design research, observed that a primary way architects gain knowledge and understanding of their subject "is through the act of designing itself, and through the experience and interpretation of other designs." 4 Traditionally hand drawing has been a primary means of designing and understanding other designs. While the sketch may be a record of an idea, observation, or discovery, sketching is a means - a process or method of thinking, interpreting, and understanding. ${ }^{5}$

\section{Field \& Documental Drawing}

Field and documental drawing is a fundamental means of developing architectural 'knowledge' and may occur at scales ranging from the traditional Grand Tour to the still life. Referential, ${ }^{6}$ prescriptive, or exploratory, the purpose of these types of drawings is to understand conditions of existing physical environments or artifacts. ${ }^{7}$ Whether seeking to understand dimension, scale, or proportion through orthographic conventions or exploring space, boundary, or light through perspective or paraline conventions, these drawings require direct, dynamically scaled relationships between the environment, the body, and the medium. Rocco Ceo suggests that through the act of drawing from plaster casts, students might learn lessons of materiality, arrangement or composition applicable to design aesthetics or paradigms at various scales. ${ }^{8} \mathrm{He}$ further suggests that the loss of traditional drawing classes in the academy is "taking its toll on architecture, where buildings often appear divorced from their sites and bear meaningless detail or articulation."

Technical documentation of an architectural work in situ may facilitate better understanding of various characteristics of a building, and this methodology has historically been of great use to architects. Measuring a column or analyzing a façade's proportions increases awareness of systems and strategies for design. This coordination of the eye, body, and hand leads the designer to perceive and understand in a more complete way how spatial, material, and temporal characteristics of architectural works are experienced than might be possible through analysis of representational data.

Perspective and pictorial documentations require a different skill set and are often more difficult to achieve, but nonetheless have their own benefits. These types of drawings provide an opportunity to get to the essence of a subject, specifically because they may not be technically precise. Through studying possible sources of drawing inaccuracies, Cohen and Bennett concluded that "the misperception of the object [likely resulting from delusion] is the major source of drawing errors." 10 In describing the drawing process, they acknowledge the warnings of significant artists and theorists ${ }^{11}$ that seeing is not the same as perceiving correctly - understanding the essence of the object drawn may be as or more important than perceiving its appearance correctly. 
These acts of observing, understanding, and recording have resonances on built work. We may look to masters of modern architecture for examples of the role of travel drawing in the development of the architect. The atmospheric qualities of Louis Kahn's enigmatic drawings, exemplified in

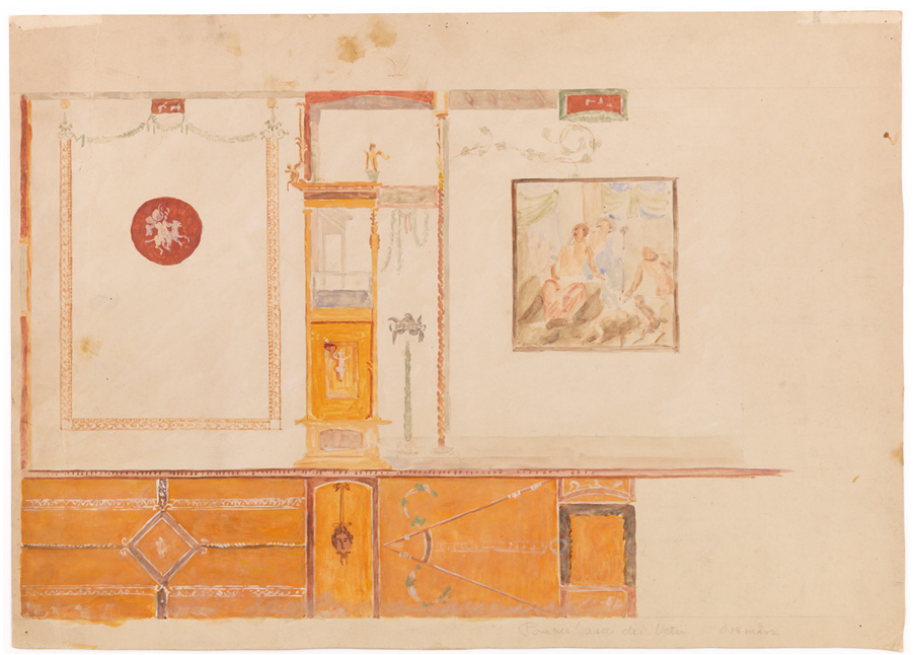

Figure 1: Pompeii Travel Sketch, Gunnar Asplund

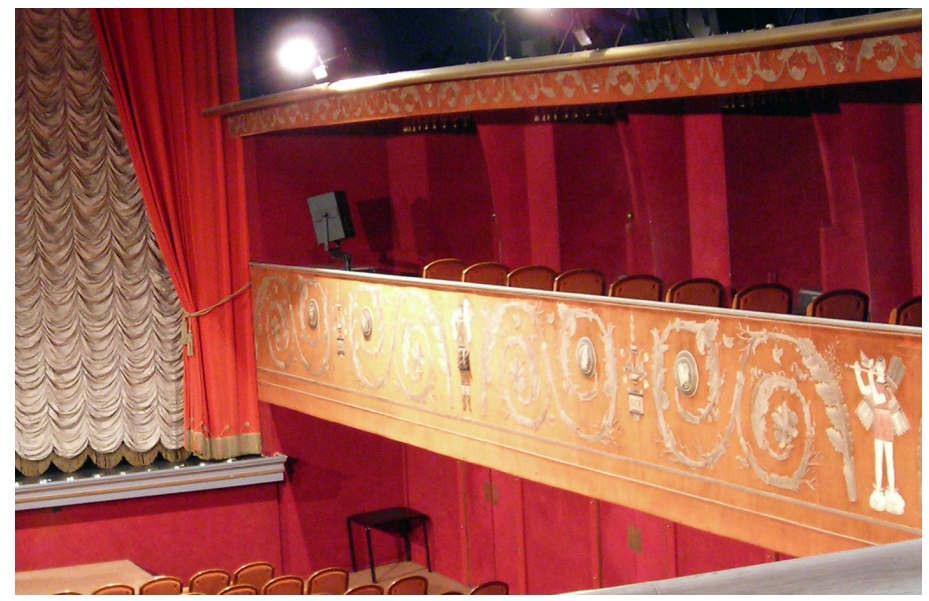

Figure 2: Skandia Cinema, Gunnar Asplund

the 1951 sketches of the Piazza del Campo in Siena and the Pyramids at Giza, arrive in many of his works as profound manipulations of material and light. In the work of Gunnar Asplund, we see a similar type of transformation, where works such as the Skandia Cinema or the Woodland Cemetery have clear relationships to the ideas and places documented as he traveled throughout the Mediterranean. The body of work of both of these architects could hardly be understood without contemplating the studies that they made while traveling. Moreover, the media with which they worked contributed to their understanding of place. Much like his buildings, the pastel or charcoal drawings of Kahn are broad and diagrammatic in quality, but rich in atmosphere, while the watercolors of Asplund express a whimsical quality that emerges in many of his projects.

\section{Design Sketching}

The design sketch, an experimental mode of expression ${ }^{12}$, is used to capture or generate the not yet existent. Sketching has traditionally initiated the architectural design process. The etymology of sketch, named as such in the $17^{\text {th }}$ century, may be traced through the Italian schizzo, to splash, and the Latin schedium, an extemporaneous poem. Its etymology suggests that the sketch is ambiguous - open to interpretation and improvisation. Contemporaneously, the sketch is understood as a rough or preliminary drawing - an unpretentious outline to be refined and developed at a later time. ${ }^{13}$ As an activity sketching provides ambiguity, and as a product the sketch anticipates iteration subsequent work will relate to previous 'outlines'. Ambiguity is critical to the creative design process. Yeoryia Manolopoulou states "accidents and mistakes, the minutest slips, the random fleeting of inconsistent ideas ... are significant aspects of the creative process that should not be neglected. The process of architectural thinking is as important as the final product because it opens new possibilities." ${ }^{14}$ Iteration is essential to the development of architectural ideas. Steven Holl emphasizes that the 'design alternatives' are 'conceptual ambitions' for a project. ${ }^{15}$ In Holl's work, hand sketches (such as his bottles of light" for the Chapel of St. Ignatius) remain necessary for developing idea-based architectural works. Reflecting on the role of hand drawing in his own process, Holl states "... you can get to the nature of an idea more quickly and therefore test the validity of a number of ideas... "16

Having media that allows one to quickly and efficiently engage multiple and sometimes fleeting thoughts, ideas and images, is critical to the process of design. Marco Frascari suggests that for Carlo Scarpa the notion of drawing was not so much about the representation of the object as it was about seeking and expressing some essence or idea. ${ }^{17}$ Scarpa's drawings and sketches reveal an overlapping of ideas and an iterative process so important to the buildings he would produce. The immediacy and accessibility of the media with which Scarpa worked (graphite, colored pencil, ink, paper) allowed him to quickly move from paradigmatic idea to detail and back again with fluidity to achieve a direct connection between ideation and work likely impossible with more compartmentalized methods and media. Scarpa's drawings had an 'unformed' quality like a sketch, and may be described as "a short record made to help memory, an observation quickly expressed in visual or linguistic form, a thought at the impulse of creation, a suggestion for something to be researched further, a free illustration of something spontaneously imagined, a drawing of seemingly insignificant detail, a proposal for future research or drawing." 18 These living, pliable graphic artifacts reflected directly on the built work that Scarpa would produce -complex and layered systems of expression. 


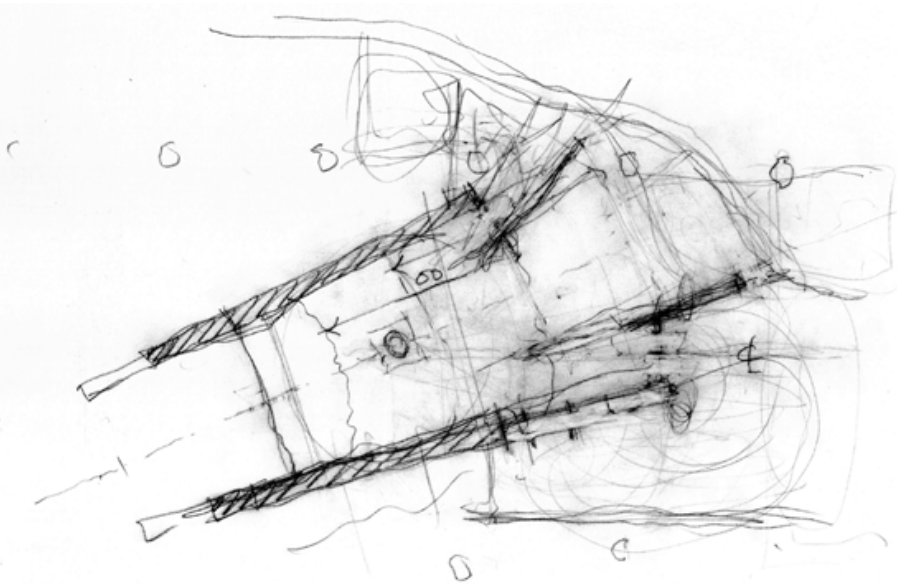

Figure 3: Design Sketch, Bernard Cywinski, FAIA

The act of sketching by hand, of putting pencil to paper in order to explore a series ideas or impulses is more than an intellectual exercise. From varying pressure in response to the paper's resistance or absorption, emerges an untrained, imaginative, graphic language. Hand sketching allows the body to fully participate in the production of the work, through the feel of the paper as the graphite is laid down, or through the emotional contact with a physical product that has no duplicate, or through various physiological and phenomenological responses. The physical attributes of the hand drawn sketch arguably precede a final product that more specifically expresses the intuitions of the designer.

Historically, hand media have been the primary means of engaging the design process because they allow accessibility and portability that, even until recently, digital media has not afforded. Whether using charcoal stick or a digital sketch mimicking program, the tool must be readily accessible, intuitive, and easy to use. Williams and Sanchez del Valle recently reviewed various digital sketch based systems, but it is unproven how intuitive or easy to use these tools are, and whether they are applicable effectively within a studio setting. So even as new hardware and software developments transform the ways in which we interface with these technologies, it is reasonable to suggest that hand media will continue to be the predominant method for investigating formal and spatial ideas as part of an iterative process, primarily because of their intuitive nature.

More recently Beryl Plimmer conducted a digital pen usability test exploring multi-model interfaces and concluded that while the pen is a more intuitive digital interface, using a digital pen alone "can be slow and inefficient."19 Tomas Dorta argues that such testing focused on task execution does not adequately assess the value of digital pens in terms of their facilitation of creativity and inspiration during the process of design ideation. ${ }^{20}$ His development of the Hybrid Ideation Space
$(\mathrm{HIS})$, developed in response to the "void of relevant digital support when it comes to generating new ideas" during the design process, is an immersive virtual environment merging the traditional sketch with digital media which has led to intriguing results when applied to an industrial design learning environment. Both of these recent examples, however, reinforce Williams and Sanchez del Valle's conclusion that "the quest to physically merge traditional hand sketching with digital mediating technologies echoes the perceived importance of the role of sketching in architectural design." ${ }^{21}$ This merging of methods and media and the fact that the digital media so far tend to mimic hand media, suggests the continued importance of hand sketching in the studio.

A medium's capacity to accommodate appropriate levels of ambiguity, iteration, and accessibility as persistent conditions of design should be a guiding principle of application and is more significant than the issue of whether and when to use hand media or digital media. But can digital media accommodate these conditions? Although it is possible for sketching as a process to occur through digital media, it is arguably fair to suggest that digital media do not afford the same opportunities for sensorial and intuitive accessibility due to the physical, emotional and temporal distance that results from the act of clicking on a mouse and viewing a constantly changing image on a monitor. ${ }^{22}$

\section{Precision Hand Drawing}

Among architecture faculty members and administrators responding to the survey, precision hand drawing is introduced into $85 \%$ of curricula during the first year. This is below the $95 \%$ for hand sketching and above the $46 \%$ for digital drawing. Today the discipline is experiencing a paradigm shift where, aided by digital modeling, information, and fabrication tools, architects are remerging with the building process from which it split in the early Renaissance. Some, perhaps the vanguard, currently call for the total abandonment of the architect's traditional postRenaissance drawing tools and their limitations. ${ }^{23}$ In many disciplines the universities are vanguards for innovation. The survey data, however, suggests that universities are situated moderately on this matter. The persistence of precision hand drawing in architectural curricula in the face of the current paradigm suggests that precision hand drawing is, for the time being, viewed as inextricably linked to the discipline of architecture and/or so far undeserving of the "scrap heap." ${ }^{24}$

\section{Drawing and Architecture's Identity}

At a time when the organization, processes, and products of the design disciplines are increasingly indistinguishable, ${ }^{25}$ perhaps the persistence of hand drawing in architecture results from a sense of loss of our disciplinary identity closely associated with hand media since the early Renaissance. A recent study determined that, in spite of recognition of the numerous advantages of digital media, architecture students 
preferred hand drawing primarily because individual authorship was more discernible ${ }^{26}$. By extrapolation, it is the unique author-identity of architecture as a discipline within the design fields that may be perceived to be at risk with the disappearance of hand drawing. The study concluded that students associated individual authorship with artistic expression and that the "stubborn resistance against total computerization, can be traced within its bonds of artistic discourse"27 rather than scientific discourse.

The printed outputs of digital media have less intrinsic value than something crafted by hand due to the expediency of the plotter. The uniquely "worked" upon (and thus 'original') condition of a hand drawing is lost in a digitally rendered plot, even when the digital construct is painstakingly made. Digital output is typical and anonymous while even a quick napkin sketch may be treasured because a particular author's hand is evident. The relative value of these modes of inscribing a surface is anecdotally evident through observation of a 2002 MOMA publication titled Envisioning Architecture: Drawings from the Museum of Modern Art documenting its architectural drawing collection. Of one hundred and forty-four plates, only two were digitally produced, with one of those two digital productions acted upon further with acrylic, presumably applied by hand. By deduction, the MOMA editor's decision to include only two digitally produced images suggest that architectural hand drawings remain the most valued by this venerable cultural institution.

\section{Designare, Disegno, Design}

The actions of the architect have not always been artistic. Prior to the Renaissance to design was to 'designate' (designare) directly upon the site the locations of key points of the structure during construction. ${ }^{28}$ Design literally 'ruled' the process of construction from within the manual building crafts. With the edification of drawing as a reliable representation of the world ${ }^{29}$ and through the rise of the artist-architect of the Renaissance came the understanding of design (disegno) as the designation upon paper of the ideas ruling an imagined structure ${ }^{30}$ allowing the artistarchitect to fully emerge from the building crafts tradition. With the formal classification of Architecture as a Fine Art coincident with the Industrial Revolution, ${ }^{31}$ Architecture as aesthetic discipline further distinguished itself from the applied arts (graphic, industrial, fashion, and interior design) that emerged from industrialization. Jonathan Hill suggests a split within architecture that resulted from the application of the term 'design' to the applied arts wherein design becomes associated with drawing an "appliance" rather than the tradition within architecture of design as drawing a form "synonymous with an idea." He goes on to say, "most people associate design with the newer design disciplines which affects how architecture design is understood. But in the discourse of architects, the older meaning of design, as drawing ideas, and the newer meaning of design, as drawing appliances, are both in evidence." 32 This infiltration of design as "drawing appliances" into architecture made it possible to conceive of the architectural work as an object and allowed the migration of object-oriented product design media into architectural practices. ${ }^{33}$

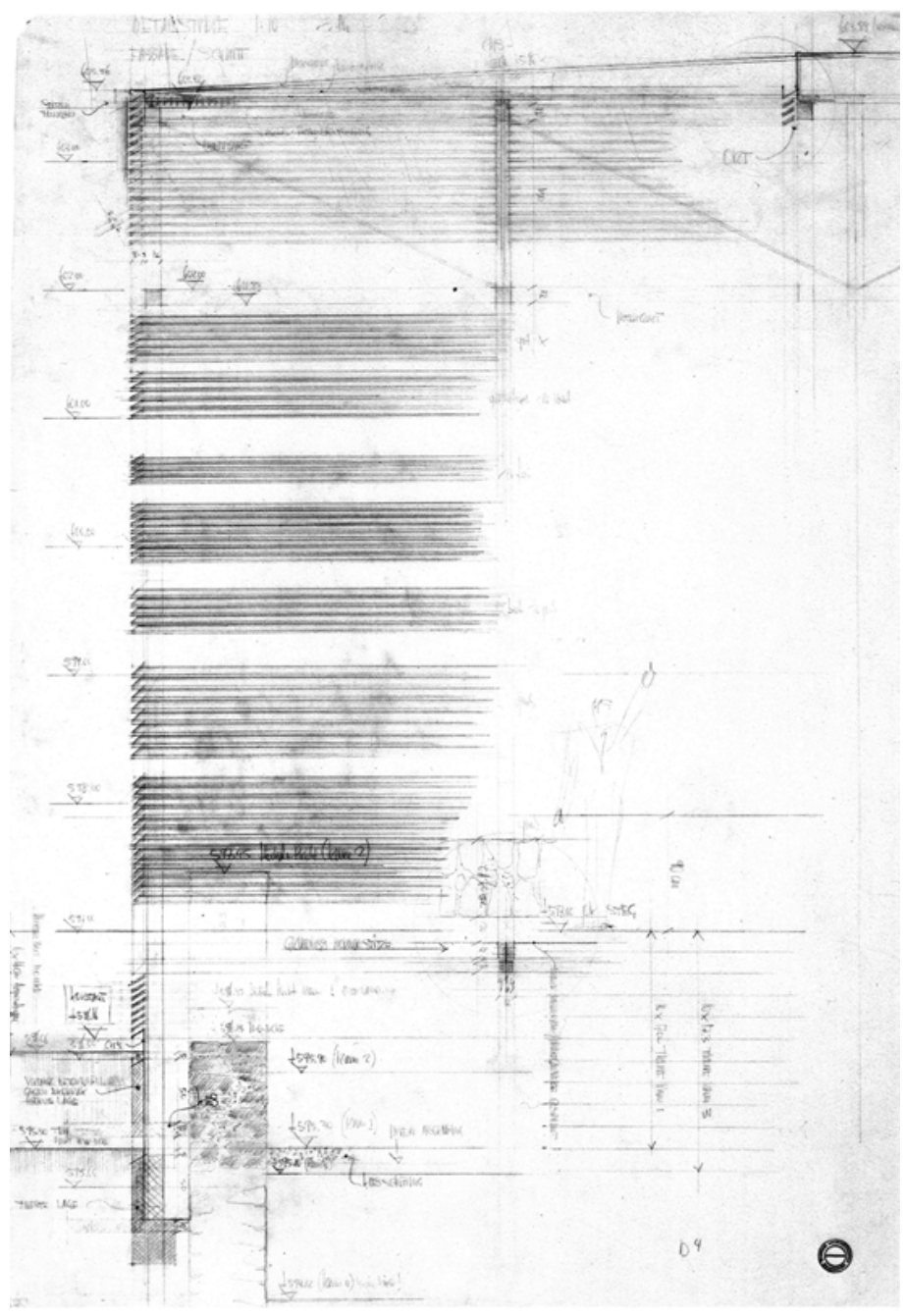

Figure 4: Precision Design Drawing, Peter Zumthor

Some have argued that the incompleteness of an abstract orthographic view associated with hand-based projection makes it a more likely vehicle for the construction within the drawing of ideas (design) while perhaps the strength of the more representational, perspective, and cinematic qualities of digital media is its ability to thoroughly describe the factual objective conditions of a building and its site. McGrath and Gardner, in their argument for the abolishment of the drawing board, distinguish hand drawing as a static "artifact" from digital drawing as a dynamic "set of information." Using digital code to parametrically manipulate a set of information describing an object may benefit the process of developing and fabricating a building. However, to describe the hand drawing as a static artifact is to oversimplify its role. Kiel Moe has observed in the digital work of his students a "disconcerting emphasis on the drawing of a building as an object rather than the drawing as a set of implied actions, performances, and effects." 34 Orthographic design drawing, embedded 
conventionally in hand drawing, designates rules of ideation, through which play continues to enrich the ideas and the experiences of the work. Peter Zumthor recognized this when he stated, "design drawings that refer to a reality which still lies in the future are important in my work." ${ }^{35}$ Hand drawings are far from static - play is made possible by the abstract and ambiguous space between orthographic projections.

The difference between these two modes of production, drawing as a "dynamic set of information" and drawing as "actions, performances and effects" and may be understood through James Carse's distinction between infinite and finite games. The rules of a finite game lead to a conclusive end while those of an infinite game extend play. The rules of an infinite game "are like the grammar of a living language, where those of a finite game are like the rules of debate. In the former case we observe rules as a way of continuing discourse with each other, in the latter we observe rules as a way of bringing the speech of another person to an end." ${ }^{36}$ While the current legal environment and emerging fabrication modes may lead construction documents to be increasingly prescriptive and finite, it is critical for the quality and development of the architectural idea that architectural design (disegno), as an infinite game played through the rules of orthographic design drawing, be extended as long as possible. Because the formal pedagogical component of an architect's education is focused specifically on architectural design thought, actions, and processes, the integration of precision hand drawing within architectural curricula is necessary for continued cultivation of design as it is distinguished within the discipline of architecture.

\section{Hand Drawing Embodies Design}

The ability to translate dimension on paper, to scale in space, is learned most effectively by simultaneously drawing, measuring and occupying in real space. A benefit of digital modeling during design is the ability to fluidly change viewpoints in perspective space and to understand formal relationships in three dimensions. However, a tendency to make design decisions predominately within perspective views increases the potential for insensitivity to scale. While procedurally the proportions of elements intersected by the picture plane correspond to the proportions of what is drawn, they do not necessarily correspond to a standard architectural scale. Experientially, the picture plane cannot be identified. The zoom command in digital media, whether in perspective or orthographic views, further compounds the potential for mis-scale. ${ }^{37}$ Paul Emmons argues that "imaginative inhabitation of the drawing" is only fully possible through bodily reference when scaling between drawing and nature ("full scale") and speculates that "perhaps this relation of the designer in the drawing ... explains why dividers were used for centuries to scale plans. The compass becomes the architect walking across the drawing." ${ }^{\prime 3}$ In describing his orthographic intensive design process, Enric Miralles stated "the process of walking may be seen as a kind of writing on the surface of the ground." ${ }^{39}$ So scale is the matter not only of body-relational proportion but, as Emmons argues and Miralles suggests, it is also the means of moving within and between the construction of the drawing and the building. Precision orthographic hand drawing, both literally and imaginatively, maintains bodily experience in the act of design.

\section{Media Conditioning}

Buildings are traces of design media. ${ }^{40}$ Carlo Scarpa is renowned for his ambiguous design palimpsests and for the intimate, sensual, and detailed conditions of his buildings. Frascari, who worked in Scarpa's studio, tells us that for Scarpa, "The drawings should express essence - some perceptual presence of an architectural idea - rather than just pretending to be a photographic substitute." ${ }^{\prime 41}$ Idea and essence are not equivocal, but Frascari's coupling of these terms suggests that not only is design primarily the act of drawing ideas rather than objects, but that it is the development of essence - drawing is an analog for qualities as much as it is for drawing forth ideas .

Among Ellen Yi-Luen Do's conclusions resulting from her study of design drawings and intention inference and automated activation software systems is that "a designer manipulates design objects through transforming shapes and locations, changing viewpoints, drawing types, and media to explore design alternatives." ${ }^{42}$ Her findings suggest that the elimination of hand drawing or any other media would only serve to limit the potential for design manipulation and thus architectural works themselves. Yi-Luen Do summarizes that "designers play mental games with themselves. They play by defining rules, selecting strategies, making design moves from the rules, and evaluating and discovering the outcome." How different might Scarpa's buildings be had he drawn solely with a single medium? What would his layered works have become without the ambiguous palimpsests of extemporaneously scaled drawings? Educators must critically consider how the limitation or omission of any design medium limits or omits particular qualities of potential architectural works.

\section{Conclusion}

Architecture has been predominantly an idea-based discipline engaging abstract imagination since the rise of the artist-architect in the early Renaissance. This identity has been closely intertwined with the means and methods associated with hand drawing. The development of various contemporary design paradigms is largely possible because of the erosion of disciplinary boundaries between the design disciplines and the emergence and influence of digital media in architectural design and production processes. These paradigms offer new ways of working and new expressions of work based largely on nonrepresentational objectification and the architect as scientist remerging with the building process. We are experiencing a monumental disciplinary shift just twenty-five years in the making in the face of centuries of tradition and inertia. Perhaps that new paradigms will extinguish traditional ones is necessary or desirable - even inevitable. 
As architects and architectural educators, how do we critically redefine the boundaries of our discipline or navigate between the paradigms afforded through the full range of media currently available to us? Digital design media, while nascent and still evolving, has become entrenched in architectural practices and education. Hand drawing media continue to persist - especially, it seems, within the academy. Perhaps with the possibility now of hindsight about both types of media and an increased disciplinary-wide facility with digital media, this is an opportune moment to assess and redefine not only our identity, but how the media we select as the means of design situates our work relative to the traditions of our discipline and other design disciplines. The aim of this paper has been to contribute to this process by reviewing how hand media have traditionally contributed to the architect's acquisition of knowledge and processes of design, and by introducing, as an indicator of how the academy is navigating this shift, quantitative survey data indicating the status of hand and digital media in architectural curricula. This is a beginning.

Initial survey data suggest that the academy may be in a dichotomous position of valuing hand and digital media equally but attending more to digital media. The survey, because it is general and its respondents limited to faculty and administrators, only provides justification for further study. The survey should be further developed and its respondents diversified to include established architectural practitioners, architectural interns, and students in recognition that our media not only conditions our work, but also us and the possible differences of values between generations. More objective research should be conducted to gain an understanding of the reasons behind the responses. For example, if the media are valued equally, why are more resources seemingly going toward digital media? Is it due, for example, to the relative 'learning' curve of each type of media? To the need for return on financial investment required for each media? Might the cause be from influences beyond the faculty or the academy? Does this suggest a misalignment between the values of faculties / administrators and other values represented by these influences?

This paper focuses on hand drawing to establish a baseline for understanding the relationships between media, design process, and disciplinary identity. The primary, traditional contributions and opportunities presented by hand drawing have been identified as directing and defining the discipline of architecture as one of ideas; creating unique opportunities for abstract, imaginative transformation; for engaging the body in design and accommodating the body in the work; and for pre-conditioning the qualities of a built work. Theoretical and empirical research has been referenced in support of these contributions and opportunities. However, there is still much to be done to validate and evaluate them relative to those afforded by digital media. Are these contributions and opportunities inherent and exclusive to hand drawing or perhaps only the result of biased understanding or momentary limitations of digital media as they continue to develop? For example, the supposition that hand drawings are more capable of ambiguity and whether such a quality in the design process leads to 'better architectural works' than digital media might be validated or discredited through empirical research. Does hand drawing result in the perception of more appropriately scaled spaces than digital media? While it is unlikely that hand media could simulate digital media, could digital media be 'hand wrought' as a means for maintaining the fullest range of media conditioning and thus architectural qualities. Perhaps the most important question, however, will continue to be a philosophical one. What should we do and become as a discipline? The media conditions but it is also a means. The position of this paper is that hand drawing must, until some clarity is achieved regarding these questions, be maintained as a necessary and integral component of a well-educated architect.

\section{Endnotes}

1 Among the Oxford English Dictionary's definitions of 'draw' is "to make (a picture) by drawing a pen, pencil, etc. across a surface" and "to cut (a furrow) with a ploughshare."

2 The survey was conducted online, over a period of approximately 3 weeks, with the assistance of the Association of Collegiate Schools of Architecture (ACSA). Faculty councilors and administrators at 134 member schools were asked a number of questions pertaining to hand drawing, sketching and digital media within their curricula. The response rate was approximately $50 \%$, with 67 schools providing responses to our questions. While not a comprehensive survey of all aspects of drawing within architectural curricula, the survey does provide some interesting insight into how various methods of delineation are perceived within the respondents' programs.

3 In discussing resources, the authors must clarify here that no information regarding fiscal resources was gathered. Rather we speak of resources in terms of the number and focus of courses being offered. One can assume, however that there are financial repercussions.

4 Bryan Lawson, "The Subject That Won't Go Away ... but Perhaps We Are Ahead of the Game: Design as Research," Arq Vol 6 No 2 (2002): 111.

5 For an expanded argument, see Daisy-o'lice I. Williams and Carmine SanchezDel-Valle, "Overlaps, Boundaries and Continuities: Transforming Sketch," Seeking the City: Visionaries on the Margins - Proceedings from the $96^{\text {th }}$ ACSA Annual Meeting (Washington, DC: ACSA Press, 2008): 547.

6 See Williams and Sanchez-Del-Valle's categorization of sketches according to three modes - referential, experimental, and analytical. Referential records/ documents an existing condition; Experimental capture/generate the nonexistent; Analytical use code or geometry to calculate the non-existent or explain the existent, 550.

7 Williams and Sanchez-Del-Valle, 550.

8 Rocco Ceo and Jose Grave De Perralta, "Drawing from Plaster Casts," Drawing from Casts: The Plaster Cast Collection at the University of Miami School of Architecture (Miami, FL: The University of Miami School of Architecture, 2008): 10-15.

9 Ceo and Grave De Perralta, 10-15.

10 Dale J. Cohen and Susan Bennett, "Why Can't Most People Draw What They See?" Journal of Experimental Psychology / Human Perception \& Performance 23, no. 3 (June 1997): 609-10.

11 Such as John Ruskin, Wang Wei and Leonardo DaVinci

12 Williams and Sanchez-Del-Valle, 550.

13 Oxford English Dictionary

14 Yeoryia Manolopoulou, "Unformed Drawing: Notes, Sketches, and Diagrams." 
Journal of Architecture v. 10 no 5 (November 2005): 523.

15 Jayne Merkel, "Art and Architecture in Analogue: Steven Holl in Conversation with Jayne Merkel." Architectural Design v. 73 no 3 (May/June 2003): 40.

16 Merkel, 40-41.

17 Marco Frascari and Martin Moeller, "The Tell-Tale Drawing: an Interview with Marco Frascari." Blueprints, v. 25 no 3 (Summer 2007): 6.

18 Manolopoulou, 519.

19 Beryl Plimmer, "Experiences with Digital Pen, Keyboard, and Mouse Usability." Journal on Multimodal Interfaces v. 2, no. 1 (July 2008): 13.

20 Tomás Dorta, "Design Flow and Ideation." International Journal of Architectural Computing v. 6, no. 3 (September 2008): 304.

21 Williams and Sanchez-Del-Valle, 547.

22 Mark McGlothlin, "Lamenting Fingerprints - Thoughts on the Passing of the Hand and Mind," Seeking the City: Visionaries on the Margins - Proceedings from the $96^{\text {th }}$ ACSA Annual Meeting (Washington, DC: ACSA Press, 2008): 535-7.

23 See Brian McGrath and Jean Gardner. Cinemetrics: Architectural Drawing Today (West Sussex, England: Wiley-Academy, 2007)

24 A reference to Le Corbusier's statement "The tool is the direct and immediate expression of progress; it gives man essential assistance and essential freedom also. We throw the out-of-date tool on the scrap heap ..." from Le Corbusier. Towards a New Architecture (NY: Praeger Publishers, 1974): 17.

25 See, for example the organization of Pentagram and Eight, Inc.; the processes of Frank Gehry and Kieran Timberlake; the exhibitions of Hewitt Cooper National Design Triennials and MOMA's Design and the Elastic Mind (2008).

26 Burcu Şenyapili and Ýncý Basa, "The Shifting Tides of Academe: Oscillation between Hand and Computer in Architectural Education." International Journal of Technology \& Design Education 16, no. 3 (October 2006): 273-283.

27 Ibid. p 273

28 Frascari and Moeller, 8.

29 Recently, see Peter Schneider, "Disegno: Drawing out the Arch-Text." Journal of Architectural Education 61, no. 1 (September 2007): 19-22. and Paul Emmons, "Size Matters: Virtual Scale and Bodily Imagination in Architectural Drawing." ARQ 9, no. 3/4 (2005): 227-235.

30 The traces of this understanding are still evident in our contemporary contract language of 'design intent' (see Atkins, Jim \& Grant Simpson, "Correlation and Intent: The Message of the Contract Documents," AIAArchitect, V 15, http://www. aia.org/aiarchitect/thisweek08/0620/0620p_risk.cfm (accessed 09.09.2008)), although perhaps it is arguable how often the contemporary intent is one of ideation.

31 See Hegel's Aesthetics: Lectures on Fine Arts

32 Hill, Jonathan, "Criticism by Design: Drawing, Wearing, Weathering." Journal of Architecture 10, no. 3 (2005): 286.

33 Consider the migration of parametric modeling programs such as CATIA into architecture and the recent emergence of object-oriented modeling programs such as REVIT.

34 Kiel Moe, "Translations from (Digital) Drawing to Building," Seeking the City: Visionaries on the Margins - Proceedings from the $96^{\text {th }}$ ACSA Annual Meeting (Washington, DC: ACSA Press, 2008): p 534.

35 Peter Zumthor, Thinking Architecture (Boston: Birkhauser, 2006): p32 as quoted in McGlothlin, 538.

36 Carse, James Finite and Infinite Games: A Version of Life as Play and Possibility (NY: Ballantine Books, 1987): 11.

37 Emmons, 232.

38 Emmons, 233. Emmons references Serlio

39 Kenneth Frampton (ed.), Technology Place and Architecture: The Jerusalem Seminar in Architecture (New York: Rizzoli, 1998): 34.

40 See McGlothin, 534. for Corona-Martinez-based discussion of media conditioning.

41 Frascari, 6 .
42 Ellen Yi-Luen Do, "Design Sketches and Sketch Design Tools," KnowledgeBased Systems v 18, no. 8 (2005): 403.

43 Yi-Luen Do, 403.

Figure Credits:

Figure 1: Watercolor, Pompeii, Gunnar Asplund, Courtesy of Swedish Architecture Museum.

Figure 2: Interior, Skandia Cinema, Gunnar Asplund, Courtesy of Francis Lyn. Figure 3: Design Sketch, Liberty Bell Center, Bernard Cywinski, FAIA; Used with permission of Bohlin Cywinski Jackson; Courtesy of Bohlin Cywinski Jackson.

Figure 4: Orthographic Drawing, Shelter for Roman Ruins, Peter Zumthor; Used with permission of Architekturbüro Peter Zumthor; Scanned from Nobuyuki Yoshida (ed.), A+U October 1998 Extra Edition: Peter Zumthor (Tokyo: A+U Publishing Co, 1998): 40. 